\title{
High Temperature Oxidation of Ultra-Low-Carbon Steel
}

\author{
L. Suarez ${ }^{1, a}$, R. Coto ${ }^{1,3}$, X. Vanden Eynde ${ }^{2, b}$, M. Lamberigts ${ }^{2, c}$ and \\ Y.Houbaert ${ }^{1, d}$ \\ ${ }^{1}$ Department of Metallurgy and Materials Science, Ghent University, Technologiepark 903, B-9052 \\ Gent, Belgium \\ ${ }^{2}$ Centre for Research in Metallurgy (CRM), Ghent - Liège, B-4000, Belgium \\ ${ }^{3}$ Department of Materials Science and Metallurgical Engineering, Oviedo School of Mines, 33004, \\ Oviedo University, Asturias, Spain. \\ a Lucia.SuarezFernandez@UGent.be, ${ }^{\mathrm{b}}$ vdeneynde@rdmetal.ulg.ac.be, \\ 'lamberigts@rdmetal.ulg.ac.be, ${ }^{d}$ Yvan.Houbaert@UGent.be
}

Keywords: oxide scales; hot rolling; oxidation rate; oxidising mechanisms; oxide composition.

\begin{abstract}
An oxide scale layer always forms at the strip surface during the hot rolling process. Its properties have a large impact on surface quality. The most important features of the oxide layer are its thickness, composition, structure, adherence and coherence. Temperature, time and gas atmosphere determine the growth of oxide layers. In this paper, the high temperature oxidation properties of ultra low carbon steels are discussed in terms of oxide growth mechanism, kinetics and phase morphology. The oxidation kinetics of ultra-low carbon steel (ULC) in air, its scale structure and composition were investigated over the temperature range 923-1473K. Oxidation experiments were performed either under controlled atmosphere or in air, to analyse the oxidation process during strip production. A first series of experiments was carried out in an electric furnace at temperatures ranging from 923 to $1473 \mathrm{~K}$, for times between 16 and 7200s. A second series was carried out in a device especially designed to control the atmosphere. After heating under pure nitrogen, the samples were oxidised in air at temperatures between $923-1323 \mathrm{~K}$ for various oxidation times. Thus treated specimens were characterised by metallography and their scale thickness was measured under the optical microscope. Scale morphology was studied and scale composition confirmed by EDS (Energy Dispersive Spectroscopy) and EBSD (Electron Backscattered Diffraction) analysis. Results show that scale growth under controlled atmosphere is significantly faster than under non controlled conditions, additionally the adherence of the scale formed in the laboratory device was significantly better than the other one. It is clear that scale thickness and constitution depend strongly on the oxidation potential of atmosphere. Computed parabolic activation energies (Ea) values are in good agreement with those found in the literature.
\end{abstract}

\section{Introduction}

During the hot rolling process, an oxide scale layer always develops at the strip surface. Characterising the structure of the scale is of great interest because it affects the frictional conditions during hot rolling and the heat-transfer behaviour at the strip-roll interface. Moreover, the scale properties affect the final steel surface quality and its response to further processing. Controlling the oxidation kinetics and mechanical properties of the oxides can then simplify pickling and improve the steel downstream behaviour.

Oxidation treatments in air at temperatures higher that $843 \mathrm{~K}$ leads to three different iron oxide layers: wustite $(\mathrm{FeO})$, magnetite $\left(\mathrm{Fe}_{3} \mathrm{O}_{4}\right)$ and hematite $\left(\mathrm{Fe}_{2} \mathrm{O}_{3}\right)$, in oxygen content increasing order, going from substrate to free surface. Below $843 \mathrm{~K}$, only the last two are thermodynamically stable [1]. According to the literature, the relative thickness fractions of these layers between $973 \mathrm{~K}$ and 
$1473 \mathrm{~K}$ are $95 \%$ wustite, $4 \%$ magnetite and $1 \%$ hematite at equilibrium, although this balance can vary from one case to another.

Depending on temperature, time, atmosphere conditions and steel chemistry, energy barriers develop, which must be overcome for an oxide to grow. Incipient oxidation layers are discontinuous and first grow by lateral extension of discrete nuclei. While nuclei are interlacing, mass transportation of ions occurs in a direction normal to the surface. The iron diffuses as cations and electrons through the oxide film. At the gas-oxide interface on the surface, oxygen is reduced to oxygen ions. The growth of the individual iron oxide layers is governed by diffusion. Therefore, temperature and time control the distance the iron atoms can travel and combining high temperatures with long times will allow the iron atoms to travel far and the concentration gradient will decrease with time. This will aid the growth of the oxide layer, since more iron atoms are made available to react with oxygen $[2,3]$.

In mathematical models used to predict the scale thickness during industrial processes, simple parabolic equations of the following type

$$
x^{2}=k(T) * t
$$

are often used (where $x=$ oxide layer thickness or weight gain, $t=$ oxidation time, $k(T)$ is temperature-dependent parabolic rate constant). On the other hand, when oxidation periods are short, the initial linear growth should be used $[1,3,4]$. Temperature is the most important parameter for the thickness of oxide layer, because $k(T)$ obeys an Arrhenius law:

$$
k(T)=k_{0} * \exp \left(-E_{a} / R T\right),
$$

where $k_{0}$ is a temperature-independent constant, $E_{a}$ is the activation energy; $R$ is the universal gas constant $\left(8.314 \mathrm{~J} \mathrm{~mol}^{-1} \mathrm{~K}^{-1}\right)$ and $T$ the oxidation temperature. The activation energy $E_{a}$, depends on both the reaction mechanism and the type of kinetics. Authors have sometimes diverging opinions on the subject: $E_{a}$ could be different for different temperature intervals and steel grades. Some use a constant $E_{a}$ for a broad temperature range; others use distinct $E_{a}$ for different $T$ ranges or propose a complex variation curve for $E_{a}[1,5,6]$. Païdassi [1] characterised the growth kinetics of pure iron in air between 973 and $1473 \mathrm{~K}$ for the three types of oxide:

$$
k_{p}\left(\mathrm{~cm}^{2} \mathrm{~s}^{-1}\right)=6.03 \exp (-169300 / R T) \text {, so , } X(\mu \mathrm{m})=24550 \exp (-84650 / R T) \sqrt{t}
$$

In the general literature, the following is found: a simple parabolic growth rate is assumed for low temperatures and sufficiently thick scale layers while a linear law is thought to prevail for high temperatures and thin oxide layers. For the transition from one oxidation mode to another, considerations about time, temperature, atmosphere conditions and steel grade are necessary. The objective of the present study is to discuss the oxide growth mechanisms, kinetics and morphology of ultra low carbon (ULC) under various conditions of oxidation atmosphere.

\section{Experimental}

The samples used in this work were obtained from ULC steel strips with the following chemical composition (Table 1):

Table 1. ULC chemical composition (wt. - \%).

\begin{tabular}{|c|c|c|c|c|c|c|c|c|}
\hline Element & $\% \mathrm{C}$ & $\% \mathrm{Si}$ & $\% \mathrm{Al}$ & $\% \mathrm{Mn}$ & $\% \mathrm{P}$ & $\% \mathrm{~S}$ & $\% \mathrm{Ti}$ & $\% \mathrm{Cr}$ \\
\hline $\mathrm{Wt} . \mathrm{\%}$ & 0.005 & 0.078 & 0.036 & 0.55 & 0.051 & 0.008 & 0.063 & 0.027 \\
\hline
\end{tabular}

The specimens used for tests carried out under uncontrolled atmosphere were $15 \mathrm{~mm} \times 15 \mathrm{~mm} \times$ $6.5 \mathrm{~mm}$ in dimensions. They were placed on refractory bases, and introduced in the electrical resistance furnace, where they were heated unprotected to different temperatures $(923,1023,1123$, 1323 and $1473 \mathrm{~K}$ ) for times between 16 and $7200 \mathrm{~s}$. They were then removed from the furnace and left to cool to room temperature in air. A thermocouple was placed on the samples surface to control the samples temperature and heating rates. 
For oxidation tests performed under controlled atmosphere, the specimens were $50 \mathrm{~mm} \times 35 \mathrm{~mm} \times$ $6 \mathrm{~mm}$ in dimensions. An original laboratory device was used to guarantee the desired treatment times ( 1 to $240 \mathrm{~s})$ and temperatures $(1223,1323$ and 1423K), the atmosphere being controlled in such a way as to better simulate the thermal and chemical conditions prevailing in the hot rolling mill. Induction heating was used, allowing fast heating while avoiding the typical long oxidation times of conventional furnaces. Two different thermocouples were placed to control the sample temperature and heating/cooling rates: one at the centre of the sample surface and the other one inside the sample in a central position. Samples were heated in a $\mathrm{N}_{2}$ flow up to the oxidation temperature. This temperature was maintained for $20 \mathrm{~s}$ to achieve a uniform temperature distribution. Dry air was then introduced into the device to oxidise the sample. The samples were kept at this temperature for times ranging from 1 and 480s to produce scales with varied thickness. $\mathrm{N}_{2}$ was flooded again during cooling down to avoid undesired further oxidation during cooling.

Scale/steel cross sections were mounted hot in a resin and ground with $\mathrm{SiC}$ paper to a 1200 grit surface finish. Finishing is performed with diamond pastes 3 and $1 \mu \mathrm{m}$ to obtain a mirror polish. After that, the cross sections were characterised and their scale thickness was measured under the optical microscope (OM). In addition, some EDS (Energy Dispersive Spectroscopy) and EBSD (Electron Backscattered Diffraction) orientation imaging was used to obtain maps for a few samples to reveal the structure of the oxide.

\section{Results and discussion}

Scale structure. Figure 1 shows some examples of the scale structure found in both oxidation tests. In the temperature range considered, samples treated in the electric resistance furnace exhibit a made of the three components described in the introduction. Air cooling has obviously led to partial wustite decomposition of the wustite. Proeutectoid magnetite crystals are clearly visible within the wustite (Figures 1(a) and 1(b)). These observations were confirmed by EDS analysis. The main problem of oxidation experiments in these conditions is that at short oxidation times, the scale layer is not uniform and adherent. Figures 1(c), (d), (e) and (f) show some examples of oxide scales after oxidation at $1323 \mathrm{~K}$ for different times under controlled atmosphere. In all cases, EBSD analyses confirmed that wustite is the major oxide layer constituent. Even for short oxidation times, the scale layer is uniform. Cross-section observations confirm a scale formation with a very good adherence to the substrate and homogeneity over the thickness. The oxide layer is essentially free of cracks, except for those few introduced during sample preparation. It is clear that controlling the atmosphere avoids the detachment of the scale from the substrate [7].

Scale growth kinetics. Figure 2 shows how scale thickness varied in tests carried out under uncontrolled atmosphere. The oxidation rate was measured using standard microscopy. This method could lead to misleading overestimates (e.g. in the case of porous scales). Nevertheless, it provides an accurate measure of the underlying kinetic processes. Scale thickness increases quickly at the beginning of the oxidation. Oxide scale growth obeys the classic parabolic law which is consistent with the transport mechanism in oxidation. 


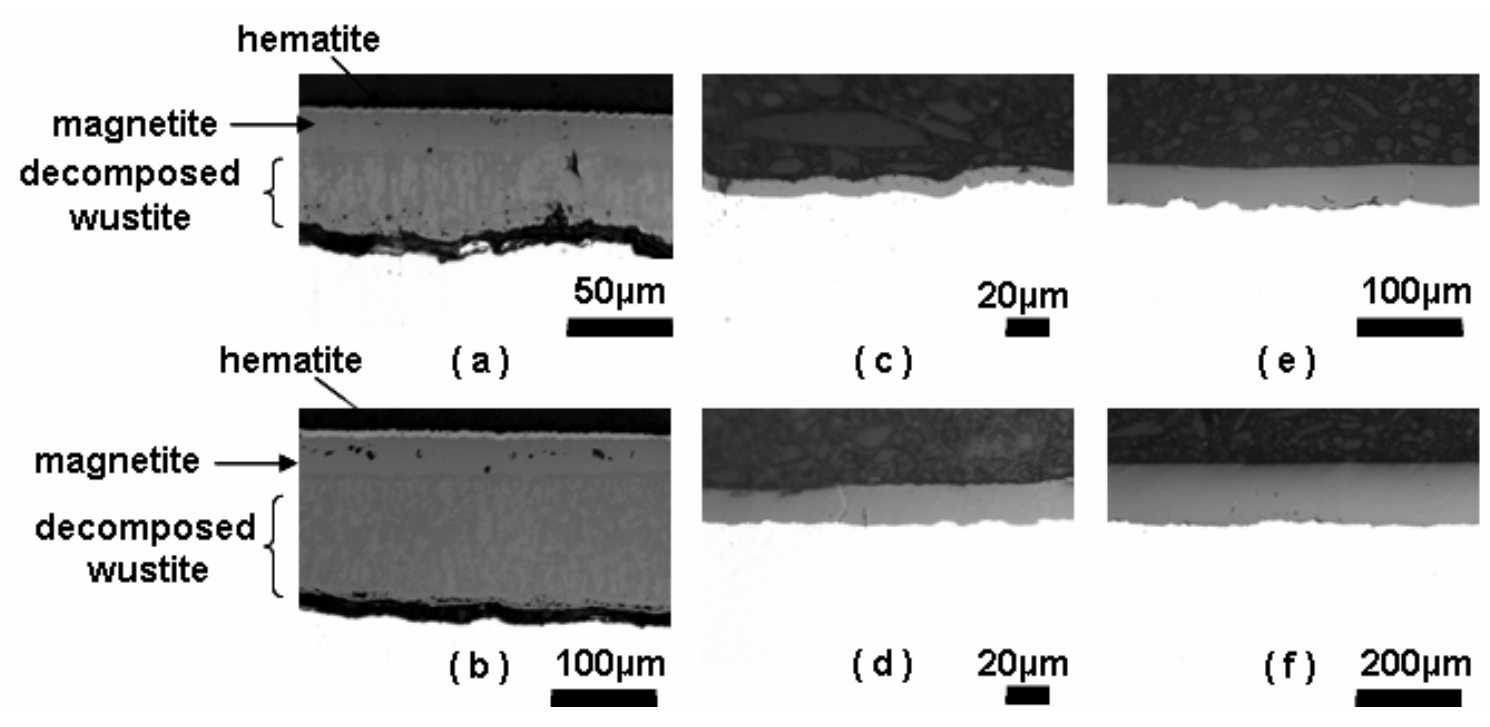

Figure 1. Cross sections of oxide scale specimens examined by OM: (a) air cooling, $\mathrm{T}_{\mathrm{ox}}=1373 \mathrm{~K}$, $\mathrm{t}_{\mathrm{ox}}=240 \mathrm{~s}$; (b) air cooling, $\mathrm{T}_{\mathrm{ox}}=1273 \mathrm{~K}, \mathrm{t}_{\mathrm{ox}}=1800 \mathrm{~s}$; (c) controlled atmosphere, $\mathrm{T}_{\mathrm{ox}}=1373 \mathrm{~K}, \mathrm{t}_{\mathrm{ox}}=4 \mathrm{~s}$; (d) controlled atmosphere, $\mathrm{T}_{\mathrm{ox}}=1373 \mathrm{~K}, \mathrm{t}_{\mathrm{ox}}=8 \mathrm{~s}$; (e) controlled atmosphere, $\mathrm{T}_{\mathrm{ox}}=1373 \mathrm{~K}, \mathrm{t}_{\mathrm{ox}}=32 \mathrm{~s}$; (f) controlled atmosphere, $\mathrm{T}_{\mathrm{ox}}=1373 \mathrm{~K}, \mathrm{t}_{\mathrm{ox}}=240 \mathrm{~s}$.

Initially, diffusion through the thin incipient scale will rapidly establish a dynamic equilibrium with the metal at the surface. When the scale becomes thicker, elemental activity across the scale layer will reduce, thus decreasing the ion flux and associated reaction rate. Then, the ion transport rate falls with time according to a parabolic rate. In addition, as the oxidation temperature increases the maximum scale thickness increases as well.

Scales thickness results under controlled atmosphere conditions are shown in Figure 3(a). Scale growth under a controlled atmosphere is significantly faster than under an uncontrolled one; additionally the adherence of the scale formed in the laboratory device was significantly more compact. It is clear that scale thickness and constitution depend strongly on the atmosphere oxidation potential.

In order to calculate the growth kinetics, the general form of the parabolic equation is applied as follows:

$$
x=K_{p} * \sqrt{t},
$$

where $x$ is the scale thickness, $K_{p}$ is the rate constant, $t$ is the oxidation time. The rate constant $K_{p}$ is expected to obey Eq.(2). Growth kinetics obtained are shown in Table 2. $E_{a}$ values obtained of 134.8 and $120 \mathrm{~kJ} / \mathrm{mole}$ are very close to the $E_{a}$ of $124 \mathrm{~kJ} /$ mole for wustite found in the literature [3].

Table 2. Oxidation kinetics

\begin{tabular}{|c|c|c|}
\hline & \multicolumn{2}{|c|}{ Scale thickness with parabolic law } \\
\cline { 2 - 3 } & $\mathrm{T}<1173 \mathrm{~K}$ & $\mathrm{~T}>1173 \mathrm{~K}$ \\
\hline $\begin{array}{c}\text { No controlled } \\
\text { atmosphere }\end{array}$ & $\mathrm{X}(\mu \mathrm{m})=8.8 * 10^{6} * \exp (-140738 / \mathrm{RT}) * \sqrt{\mathrm{t}}$ & $\mathrm{X}(\mu \mathrm{m})=12.4 * 10^{5} * \exp (-134806 / \mathrm{RT}) * \sqrt{\mathrm{t}}$ \\
\hline $\begin{array}{c}\text { Controlled atmosphere } \\
\text { No data avalaible }\end{array}$ & $\mathrm{X}(\mu \mathrm{m})=5 * 10^{5} * \exp (-119963 / \mathrm{RT}) * \sqrt{\mathrm{t}}$ \\
\hline
\end{tabular}



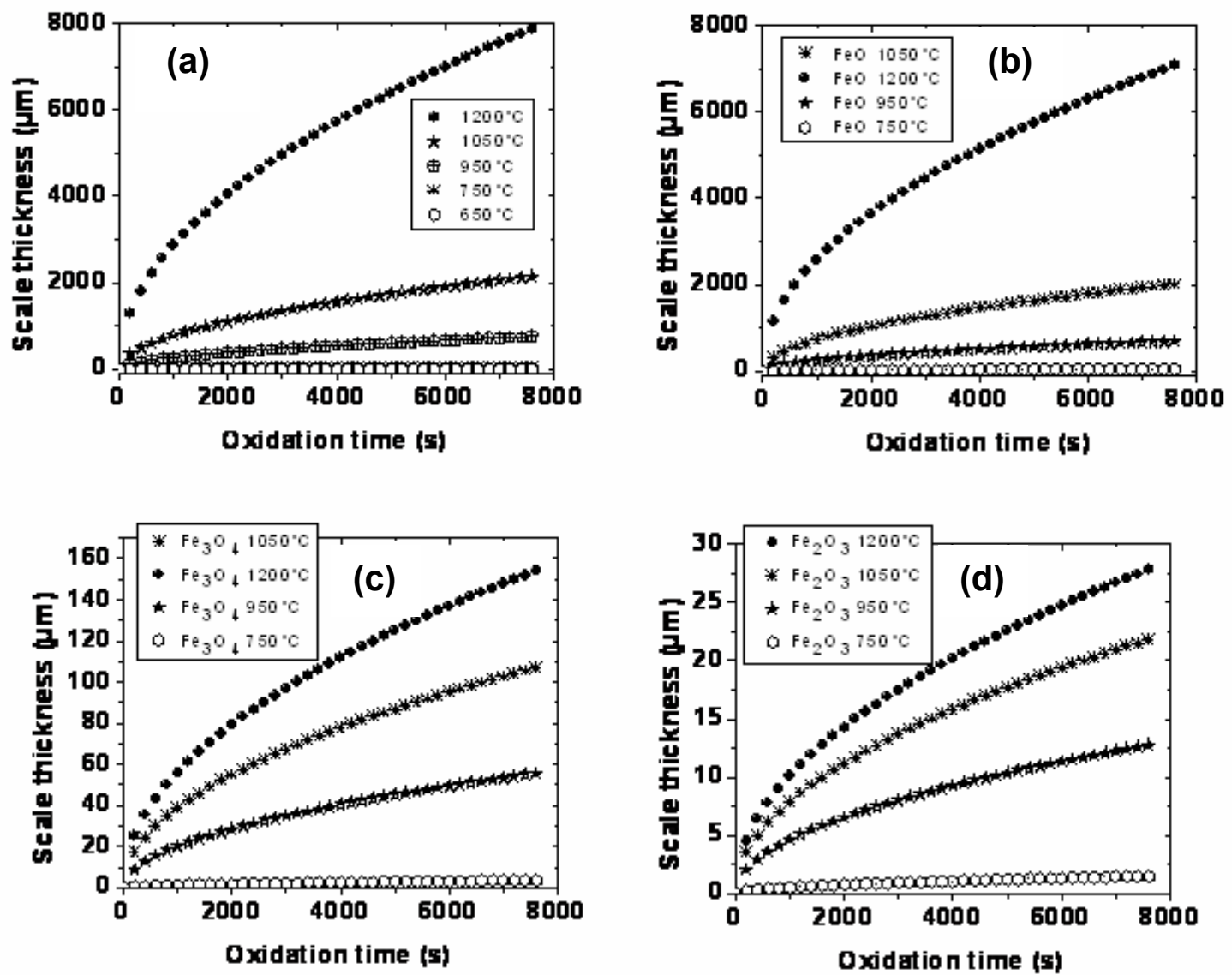

Figure 2. Thickness of the oxide scales formed under no controlled atmosphere (oven-air cooling): (a) Total scale thickness for different T; (b) FeO thickness grown in $1023-1473 \mathrm{~K}$; (c) $\mathrm{Fe}_{3} \mathrm{O}_{4}$ thickness grown in 1023-1473K; (d) $\mathrm{Fe}_{2} \mathrm{O}_{3}$ thickness grown in 1023-1473K.
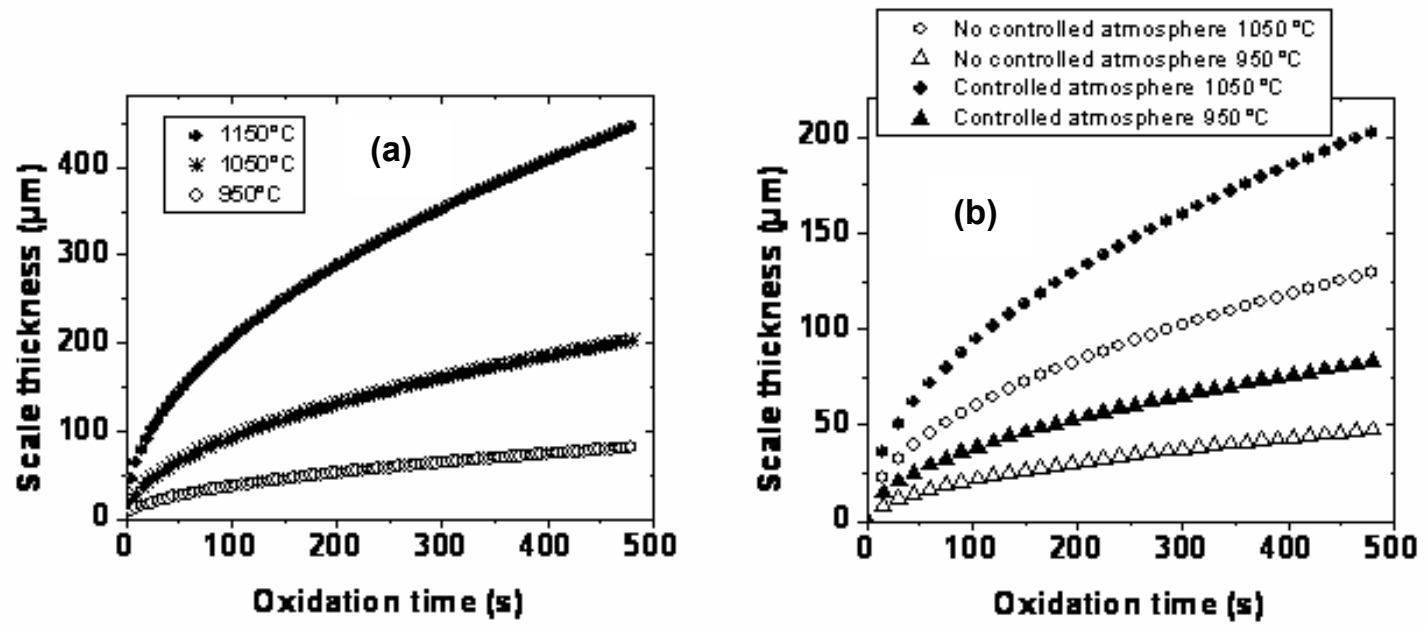

Figure 3. (a) Thickness of the oxide scales formed under controlled atmosphere $\left(\mathrm{N}_{2}\right.$-dry air- $\left.\mathrm{N}_{2}\right)$ for different $t$ and $\mathrm{T}$. (b) Comparison between scales thickness grown in both oxidation atmospheres. 


\section{Conclusions}

- The oxidation rate of steel at $1023,1123,1223,1323$ and $1473 \mathrm{~K}$ with air cooling has been studied. Also, oxidation rates at 1223, 1323 and 1423K under controlled atmosphere conditions have been analysed. In both cases, results are in agreement those found in the literature.Scale thickness increases quickly at the beginning of the oxidation, following a parabolic law as the oxidation time increases. This is consistent with the transport mechanism in oxidation.

- Cross-section observations indicated that the oxide scales exhibited distinct structures and thicknesses depending on the atmosphere control considered. When gas-protection is applied the oxide scales formed were a single wustite layer, thin and compact, and macroscopically a single layer. They were similar to the secondary or tertiary scales formed during hot rolling of steel, with a minimum thickness of less than $2 \mu \mathrm{m}$ at $1323 \mathrm{~K}$. In contrast, when heating in air, the scales formed were thick, non adherent to the substrate and essentially composed of multilayers.

- For the experiments with air cooling, the morphology of the oxide scale on the steel surface is in agreement with information provided in the literature: scale contains three layers: hematite, magnetite and wustite after any oxidation period. The wustite phase is dominant with the hematite fraction remaining low at all temperatures. Generally, the scale layer thickness of magnetite increases with temperature. Results have shown that during cooling wustite transform to magnetite due to the saturation of oxygen during cooling.

- Scale growth under a controlled atmosphere allows producing a single layer of essentially pure wustite. It grows significantly faster than under an uncontrolled atmosphere. The scale formed in the laboratory device was also significantly more adherent.

- The scale growth rate is strongly temperature-dependent. Parabolic activation energies $E_{a}$ values are in agreement with literature.

\section{Acknowledgements}

This research was carried out within a common project involving Ghent University and the Centre for Research in Metallurgy (CRM), Belgium.

\section{References}

[1] J.Païdassi: Acta Metal. Vol.6 (1958), p. 184

[2] G.Béranger, G.Henry and G.Sanz: The book of the steel, (Tech. \& Doc Lavoisier, Paris, 1994).

[3] M. H. Davies, M. T. Simnad and C. E. Birchenall: J. Metal (1951), p. 889

[4] P. Kofstad: High Temperature Corrosion (Elsevier Applied Science Publishers, London 1988).

[5] P. A. Munther and J. G. Lenard: J. Mater. Proc. Techn. Vol. 88 (1999), p. 105

[6] V. Gonzalez, P. Rodriguez, Z. Haduck and R.Colas, Ironmak. and Steelmak. Vol.28 (2001), p.1

[7] L. Suarez, G. Bourdon, X. Vanden Eynde, M. Lamberigts and Y. Houbaert: Proc. Int. Conf. Processing and manufacturing of advanced materials, THERMEC 2006 (Vancouver University, Vancouver 2006). Available on November 2006. 